\title{
PRÁXIS NO ENSINO DE ESTRUTURAS ORGANIZACIONAIS: CRIATIVIDADE, LUDICIDADE E JOGOS.
}

\author{
RIO DE JANEIRO/RJ JUNHO/2018 \\ Maria Aparecida Santos de Oliveira - UNISUAM - aparecidasantos@souunisuam.com.br \\ Carlos Eduardo José da Sllva - Unisuam - eduardocejs@fab.mil.br
}

Tipo: Relato de Experiência Inovadora (EI)

Categoria: Métodos e Tecnologias

Setor Educacional: EDUCAÇÃO SUPERIOR

\begin{abstract}
RESUMO
Este artigo aborda o uso das Metodologias Ativas na Aprendizagem como recurso didático na formação do estudante de nível superior, no curso de Administração do Centro Universitário Augusto Motta. No quarto período do curso os alunos devem aprender a estruturar organizações, identificando qual a melhor estrutura de acordo com a especificidade da organização. Através da metodologia sala de aula invertida, onde o material teórico se encontra em ambiente virtual, foi aplicada a experiência prática do uso de jogo quebra cabeça para construção de estrutura organizacional. A ideia central foi que o aluno leu previamente as principais explicações e estudou o material indicado. $O$ encontro presencial é uma oportunidade para esclarecer dúvidas, realizar atividades, trocar conhecimentos e fixar a aprendizagem, conduzindo o aluno a interiorizar o conteúdo de forma prática e torná-lo capaz de solucionar os problemas reais apresentados no contexto organizacional e fazer com que aluno pratique o processo decisório.
\end{abstract}

Palavras-chave: Práticas educativas; sala de aula invertida; aprendizagem híbrida; tecnologias educacionais; inovação pedagógica

\section{AGRADECIMENTOS}

CARLOS EDUARDO JOSÉ DA SILVA PELA CONTRIBUIÇÃO À CONFECÇÃO DESTE ARTIGO, ATRAVÉS DE SUA EXPERIÊNCIA ACAD EMICA 


\section{Introdução}

As pessoas aprendem de diversas formas. O processo de ensino e aprendizagem baseado na transmissão de informação tem sido constantemente criticado como sendo antiquado e ineficaz. Na sala de aula tradicional o argumento utilizado é que as aulas expositivas partem do pressuposto de que todos os estudantes aprendem no mesmo ritmo e absorvendo informação ouvindo o professor.

Revolucionando a forma de ensinar, a base do conceito de inversão da sala de aula é fazer em casa o que era feito em aula, por exemplo, assistir palestras, vídeos e proceder leituras essenciais à construção do conhecimento e, em aula, o trabalho que era feito em casa, ou seja, resolver problemas (BERGMANN e SAMS, 2012).

Em síntese, significa transferir eventos que tradicionalmente eram feitos em aula para fora da sala de aula, segundo Lage, Platt e Treglia (2000).

A sala de aula invertida ou flipped classroom é uma abordagem pela qual o aluno assume a responsabilidade pelo estudo teórico e a aula presencial serve como aplicação prática dos conceitos estudados. (JAIME; KOLLER; GRAEML, 2015).

A proposta dos autores foi de trabalhar com métodos de ensino alternativos, explorando a colaboração, a investigação e o fazer, e não apenas reter a informação. Reconhecemos que o aluno precisa ter um papel ativo para significar e compreender essa informação segundo conhecimentos prévios, construir novos conhecimentos, e saber aplicá-los em situações concretas.

Foi usada a metodologia sala de aula invertida por reconhecer a necessidade de ter mais tempo em sala de aula para atividades práticas e exercícios. A proposta foi inverter a prática tradicional da sala de aula, usando como recurso digital o ambiente virtual de aprendizagem, onde os alunos estudam previamente os conteúdos e em sala de aula realizaram atividade lúdica quebra cabeça para montagem de organogramas, na disciplina Modelagem Organizacional.

\section{Introdução}

A práxis é considerada uma etapa necessária na construção de conhecimento válido. A teoria é implementada nas aulas e foca-se na abstração intelectual; a práxis, por sua vez, ocorre a partir do momento em que essas ideias são experimentadas para continuar com uma contemplação para se pensar nos seus resultados. 
Práxis significa ação. Portanto, em educação, a práxis pedagógica significa a prática de ensino. Ou seja, o professor coloca seus saberes em ação para transformar o ambiente e aqueles que estão nele inseridos. Práxis é uma palavra com origem no termo em grego praxis que significa conduta ou ação. Corresponde a uma atividade prática em oposição à teoria.

O quebra-cabeças, as cores, os tamanhos, as variedades de peças possibilita um desafio para jogar sozinho, em dupla ou em grupo. Para efeito deste estudo, os docentes se aproveitaram de 4 turmas da disciplina MODELAGEM ORGANIZACIONAL, uma média de de 220 alunos matriculados no Centro Universitário Augusto Motta Curso de Administração - RJ, onde os alunos deveriam aprender a estruturar organizações. Foi pensado, pelos autores, um jogo, onde os alunos pudessem montar um organograma, com o jogo quebra-cabeças.

Através do material E.V.A., através de retângulos e hastes de polietileno, foi idealizado um estudo de caso, do qual os alunos deveriam demonstrar uma estrutura organizacional tradicional, hierarquizada, com diversos níveis hierárquicos.

Ao longo da atividade, deveriam seguir às ordens do docente: downsizing (retirar cargos que não tinham mais o porque de existir, intercalar e criar fluxos de informações entre as áreas, formando, assim, uma estrutura horizontalizada, bem como terceirizar áreas e criara staffs.

Os objetivos da aprendizagem foram: estimular o conhecimento; desenvolver a atenção e o pensamento lógico; favorecer o desenvolvimento da atuação da memória; desenvolver diferentes habilidades do pensamento como: observar, comparar, analisar e sintetizar.

Os quebra-cabeças permitem o desenvolvimento de habilidades espaciais e geométricas como: "a visualização e o reconhecimento de figuras, a análise de suas características, a observação de movimentos que mantêm essas características, a composição de figuras, a percepção da posição e distâncias, o enriquecimento do vocabulário geométrico e a organização do espaço através da movimentação das peças." (SMOLE; DINIZ; CÂNDIDO. 2003, p. 87)

\section{Desenvolvimento da experiência acadêmica.}

Nesta disciplina, Modelagem Organizacional, refletiremos sobre questões sobre as práticas educativas presentes nas salas de aula, numa perspectiva lúdica, onde a criatividade deve ser a mola propulsora no processo ensino aprendizagem. 
Como professores, sabemos como está difícil motivarmos nossos alunos, frente à toda tecnologia estimulada na atualidade. Porém, acreditamos que a sala de aula é para todos, jogos, brincadeiras e estratégias de ensino diferenciado devem ser utilizados em todos os níveis escolares para atender à diversidade presente no sistema educacional.

Considerando o quebra cabeças como jogo de peças, em que o objetivo é encaixar no lugar certo a peça correta, em que o objetivo consiste em encaixá-la no lugar correto e no fim montar uma imagem ou algo parecido, os autores idealizaram um estudo de caso, em que os alunos deveriam montar uma estrutura organizacional, através de um organograma, através de peças de E.V.A. e hastes de polietileno, a estrutura descrita nos três níveis hierárquicos (institucional, tático e operacional).

Durante o semestre 18.1, os alunos, através do ambiente virtual de aprendizagem, leram o material teórico, o qual foi discutido em sala de aula, ambiente onde as dúvidas foram retiradas e aplicadas através da prática citada neste estudo.

Ao longo da aplicação em 4 turmas, turnos da manhã e noite, média de 220 alunos, foram observadas diversas experiências de aprendizagem.

\section{Resultados sobre a experiência}

$1^{\text {a }}$ fase - Foi proposto o seguinte estudo, o qual os alunos deveriam alocar as peças de acordo com uma estrutura hierarquizada e tradicional, considerando seus estudos e vivência profissional.

"A empresa do setor industrial COMETA S.A. contratou você como consultor empresarial para representar graficamente os setores da organização, distribuídos da seguinte forma:

a. Conselho de Administração

b. Presidente

$\because$ Há um assessor para o presidente, contratado como funcionário.

c. Vice-presidente

d. Superintendente

e. Diretor Geral

f. Diretor Administrativo/Financeiro

. Há staff de Assessoria Contábil externa à empresa.

g. Diretor Comercial

. Há staff de empresa externa contratada para fazer Pesquisa de Mercado 


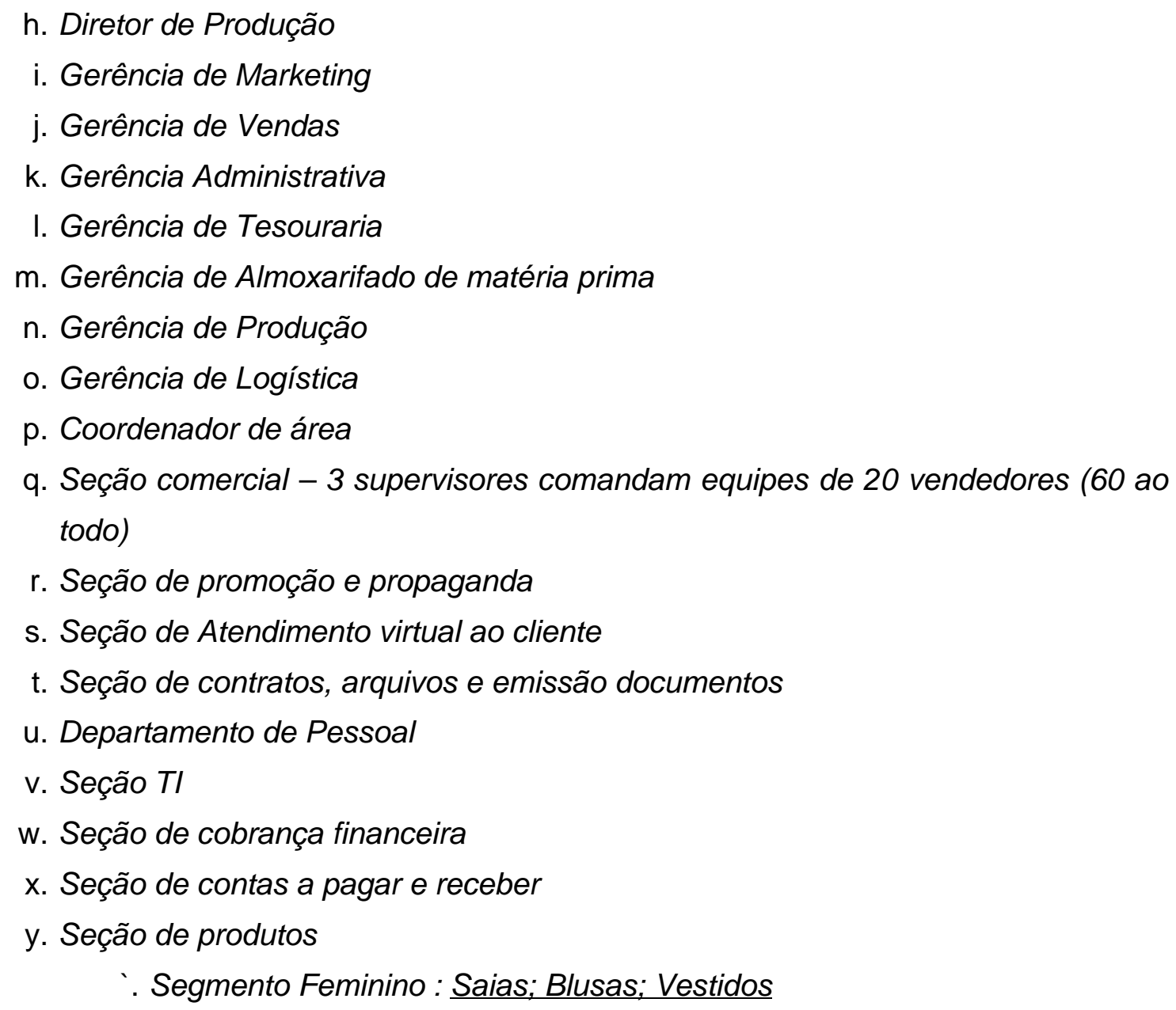

- Segmento Masculino: Calças; Camisas; Bermudas

a. Seção de entregas"

$2^{\text {a }}$ fase - Os alunos deveriam idealizar, através do comando docente, a exclusão de níveis hierárquicos e cargos e terceirizações para horizontalizar a organização, estando livre para excluir e incluir áreas de acordo com os objetivos organizacionais.

$3^{\text {a }}$ fase - Avaliação - os alunos deveriam retratar essas estruturas organizacionais através da,abstração, com desenhos organizacionais, com afolhas A3 e réguas de desenho geométricos.

4a fase - Resultados - em feedback dos alunos, pudemos constatar, que através da técnica de construção e abstração dos conteúdos, houve facilidade de absorção da matéria.

\section{Proposta de reflexão sobre essa temática}


Compreendendo a importância da criatividade para o atendimento das diversidades presentes na sala de aula e conhecendo as diversas atividades lúdicas e jogos que favorecem a aprendizagem, utilizamos como estratégia de ensino uma atividade de jogo e para alcançar o objetivo da disciplina: estruturação de empresas.

A criatividade consiste em surpreender fazendo algo diferente, experimentando novas possibilidades, novas estratégias e ela é uma qualidade que todo ser humano pode demonstrar em sua maneira de viver o dia-a-dia.

Ludicidade é envolver-se numa atividade, utilizando objetos, em geral brinquedos, que trazem prazer à criança. Neste contexto, o papel dos professores foram de auxiliar o aluno a aprender um novo conteúdo com o uso de estratégias e atividades prazerosas.

Os autores crêem que o objetivo deste estudo foi estabelecer relações entre: jogo, ludicidade, criatividade e educação, e que foi refletivo neste artigo.

\section{Conclusão}

O aluno é o centro do processo de ensino aprendizagem e a construção do conhecimento se dá de maneira horizontal e coletiva.

Pensar em metodologias ativas é pensar no aluno. É pensar no futuro da educação.

Uma educação ativa promove uma sociedade proativa, com seres pensantes que participam, colaboram e produzem.

Uma educação que promove um pensamento crítico e reflexivo sobre os problemas e desafios de nossa sociedade.

Uma educação que transforma a visão do educando em relação ao seu desenvolvimento e do meio em que está inserido

Atualmente, ainda sobrevive em grande parte das instituições de ensino principalmente de nível universitário e nas áreas de humanas - um modelo de ensino tradicional - em que o professor é o centro do processo de ensino-aprendizagem, enquanto o aluno um mero receptor de informação.

Mas para reformular é necessário destruir obstáculos e construir um novo paradigma de ensino. 
Esses obstáculos estão apoiados em alguns pilares essenciais: instituição de ensino, docente, discente, currículo e infra-estrutura.

A instituição de ensino deve apoiar o ensino participativo, com a ação do corpo docente. A preparação do material didático com a participação dos professores é bem mais trabalhosa do que um curso tradicional e exigirá mais tempo e tecnicidade. É dever da instituição apoiar e fornecer o devido suporte ao seu corpo docente.

Com relação ao docente, é fundamental que o professor passe a enxergar seu papel como o de um "coach", responsável por fazer seu aluno "aprender a aprender" e não ser o centro da informação e conteúdo.

No que se refere ao aluno, o "coach" deve fazê-lo refletir para abandonar sua zona de conforto e da passividade. O docente deve orientar o aluno a construir seu próprio processo de ensino, e este caminho certamente não é o mais fácil e confortável, por isso podem haver resistências.

Finalmente, o currículo da instituição não deve ser apenas conteudista e recortado como uma tabela periódica. Seu Projeto Pedagógico deve refletir as habilidades e competências que se buscam como resultado em cada semestre, ano e do curso como um todo.

Um outro aspecto fundamental é a infraestrutura, ou seja, qual é o papel da sala de aula, em quais momentos haverá o encontro presencial? Quais espaços devem ser ideais para preparações prévias, ensino baseado em projetos, entre outros?

Enfim, este estudo não é ó encerramento, mas o início de uma discussão acadêmica sobre o papel do professor frente às novas tecnologias e às técnicas já existentes que podem ser aproveitadas para o ensino aprendizagem.

\section{Bibliografia}

BERGMAN J. e SAMS, A. (2012), Flip Your Classroom: Reach Every Student in Every Class Every Day, USA, International Society for Technology in Education.

EDUCAUSE. Things you should know about flipped classrooms. 2012. Disponível em: . Acesso em: 19 jul. 2013.

JAIME, M. P.; KOLLER, M. R. T.; GRAEML, F. R. La aplicación de flipped classroom en 
el curso de dirección estratégica. In: JORNADAS INTERNACIONALES DE INNOVACIÓN UNIVERSITARIA EDUCAR PARA TRANSFORMAR, 12., 2015. Actas... Madrid: UNIVERSIDAD EUROPEA, 2015. p. 119-133.

LAGE, M. J.; PLATT, G. J.; TREGLIA, M. Inverting the classroom: A gateway to creating an inclusive learning environment. The Journal of Economic Education, v. 31, p. 30-43, 2000.

SMOLE, K. S.; DINIZ, M. I.; CÂNDIDO, P. Figuras e formas. Porto Alegre: Artmed, 2003. 